\title{
Technology Transfer and Commercialization as a Source for New Revenue Generation for Higher Education Institutions and for Local Economies
}

\author{
Richard S. Katzman and Ricardo Azziz
}

\section{Introduction}

The basic and underlying mission of most universities is two-fold: knowledge transmission (education and training) and knowledge generation (research and scholarship). The fundamental challenge for these organizations is that this mission often comes with costs that are difficult to cover, thus creating significant financial burdens. In general, neither education nor research operate in a business model that allows the opportunity to generate any substantial excess of revenue over expenses (e.g. profit or margin). Moreover, both missions require substantial ongoing investment for these organizations to remain academically competitive and market relevant. Compounding the challenge, from a community perspective, is that universities often serve as critical economic engines for the cities and towns where they are located. Universities support local area businesses, housing, schools, healthcare facilities, and a host of other economic drivers vital to the health of these municipalities.

The issue is therefore to identify new and meaningful sources of revenue that can be used to augment the organization's immediate and long-term needs to maintain and expand their infrastructure. Technology Transfer represents one such opportunity where investment of resources can yield a return which can then be cycled back into the university for its further growth and development.

R. S. Katzman

Lundquist Institute at Harbor-UCLA Medical Center, Torrance, USA

\section{R. Azziz (ه)}

Health Policy, Management, and Behavior, School of Public Health, University at Albany, SUNY, Albany, USA

Obstetrics//Gynecology and Medicine, University of Alabama at Birmingham, Birmingham, USA

Tellurian Global, LLC, Vestavia, USA

\section{The Business of Technology Transfer}

\subsection{What Exactly is Technology Transfer}

Technology transfer is a commonly used term that often means different things to different people and the organizations within which it is functioning. At its core, technology transfer (also known as 'Tech Transfer') is:

The process of transferring (disseminating) technology from a person or organization that owns or holds it to another person or organization. It occurs along various planes: (1) among universities, (2) from universities to businesses (and vice versa),

(3) from large businesses to smaller ones (and vice versa),

(4) from governments to businesses (and vice versa), across geopolitical borders. [1]

The goal for tech transfer is to bring new discoveries to market, either individually or collectively, creating a product or service and making it available. The result is society benefits as a collective, and those bringing this technology to the marketplace create an economic value for themselves and those who were involved with its discovery and commercialization.

\subsection{The Regulatory Framework for Technology Transfer}

To understand why tech transfer has become such an important tool for universities and so critical to the entire consumer market, it is useful to first understand its regulatory protection.

\subsubsection{The Bayh-Dole Act (U.S.)}

Introduced by Senators Birch Bayh (Democrat from Indiana) and Robert Dole (Republican from Kansas) in the United States (U.S., the Patent and Trademark Act Amendments (P. L 96-517) was passed into law in 1980. This law enabled universities to retain ownership of new inventions and 
discoveries through use of patents and copywrite protection while also pursuing commercialization. The Bayh-Dole Act, as it has become known, defined a uniform patent policy among the U.S. federal agencies that funded research, enabling universities, non-profit organizations, and for-profit businesses to retain ownership. It also created a mechanism and system to incentivize these organizations and their investigators to document, capture and monetize the value of this intellectual property (IP) [2].

Importantly, this legislation provided a legal framework upon which industrialized countries around the world could: (1) pursue similar goals related to research, development, and commercialization; and (2) form meaningful partnerships across international borders. Prior to passage of this legislation, laws governing IP and inventions, in the U.S. and globally, were vague and inconsistent, making it difficult for inventors and scholars to protect their discoveries. This then was a disincentive to universities and their researchers to invest in proper protection for the eventual sale and distribution of these new technologies. Consequently, many opportunities were lost, and new technologies were not being leveraged and optimized to enable and achieve a proper level of economic benefit.

The Bayh-Dole Act is "perhaps the most inspired piece of legislation to be enacted in America over the past half-century," according to 'The Economist' magazine. In "Innovation's Golden Goose," an opinion piece published in Dec. 12, 2002, the respected publication states that, "Together with amendments in 1984 and augmentation in 1986, this [Act] unlocked all the inventions and discoveries that had been made in laboratories throughout the United States with the help of taxpayers' money. More than anything, this single policy measure helped to reverse America's precipitous slide into industrial irrelevance" [2]. The effects of the Bayh-Dole Act, as will be discussed, have critically accelerated invention and creativity, and their commercialization, for universities in the U.S. and around the world.

\subsubsection{Other Countries with Legislation Similar to the Bayh-Dole Act}

The Bayle-Dole Act serves not only as a guide to U.S. tech transfer, but as a model legislation fort the rest of the world.
Since passage of the initial legislation in 1980, that process which defines discovery to product development to commercialization has become the standard for a worldwide "Discovery-Entrepreneurial Ecosystem". Today, tech transfer has been embraced around the globe (Table 1). It has become a critical source of revenue for universities and a primary pipeline of new products and services across all industries. During the past 40-years, countries around the world have developed and implemented their own versions of this legislation. This has enabled and incentivized more active scientific cooperation across international borders.

\subsection{Protecting and Managing Technology Innovation and Investment}

To ensure that an inventor or researcher, and their institution, can benefit from their discoveries and, in turn, ensure that the idea is moved to its full realization and commercialization for the benefit of the larger society, it is critical that there be a regulatory and legal framework that protects these ideas. Often the terms patent, copyright, and trademark are confused. Although there may be some similarities among these kinds of IP protection, they are different and serve different purposes.

\subsubsection{What is a Patent?}

A patent for an invention is the grant of a property right to the inventor. In the U.S. it is issued by the U.S. Patent and Trademark Office (USPTO). Generally, in the U.S. the term of a new patent is 20 years from the date on which the application for the patent was filed or, in special cases, from the date an earlier related application was filed, subject to the payment of maintenance fees. U.S. patent grants are effective only within the U.S., U.S. territories, and U.S. possessions. Under certain circumstances, patent term extensions or adjustments may be available.

The right conferred by the patent grant is, in the language of the statute and of the grant itself, "the right to exclude others from making, using, offering for sale, or selling" the invention in the U.S. or "importing" the invention into the U. S.. What is granted is not the right to make, use, offer for
Table 1 Countries with legislation similar to the U.S. Bayh-Dole Act

\begin{tabular}{l|l|l}
\hline Brazil [425] & Japan [49,702] & Russia [555] \\
\hline China [17,754] & Malaysia [258] & Singapore [1064] \\
\hline Denmark [1,271] & Mexico [376] & South Africa [173] \\
\hline Finland [1,563] & Norway [138] & South Korea [21,817] \\
\hline Germany [17,326] & Philippines [86] & United Kingdom [7599] \\
\hline $\begin{array}{l}\text { Italy [3386] } \\
\begin{array}{l}\text { Note The numbers in brackets indicate the number of patents each country was awarded by the USPTO in } \\
\text { 2018 } \\
\text { Adapted from [3] }\end{array}\end{array}$ \\
\hline
\end{tabular}


sale, sell, or import. Rather, it is the right to exclude others from making, using, offering for sale, selling, or importing the invention. Once a patent is issued, the patentee must enforce the patent without aid of the USPTO [4]. In other words, under U.S. regulation having a patent gives one the right to sue others for infringement, but does not mean the USPTO will enforce such infringement. A critical distinction and something other countries wishing to enhance their tech transfer capabilities may want to assess.

Other than seeking patent protection in their own country, inventors can also seek international patent protection. The Patent Cooperation Treaty (PCT) [5] was signed in 1970 and amended subsequently. By filing one international patent application under the PCT, applicants can simultaneously seek protection for an invention in a large number of countries. The PCT assists applicants in seeking patent protection internationally for their inventions, helps patent offices with their patent granting decisions, and facilitates public access to a wealth of technical information relating to those inventions.

There are various avenues to assist inventors in pursuing international patents. For example, the Office of International Patent Cooperation (OIPC) under the USPTO was established in 2014 to support and improve the international patent system. The office leads efforts to assist U.S. inventors and businesses in protecting their patent rights worldwide and supports the global innovation community. The World Intellectual Property Organization (WIPO) was established in 1967 and is a self-funding agency of the United Nations, with 193 member states. WIPO serves as the global forum for IP services, policy, information, and cooperation. This, patent protection in one country can also be sought by inventors from other countries.

In 2018 the USPTO provided 178,184 patents to inventors from a total of 123 countries [3, 6]. Table 2 provides an overview of those countries that had the most active research and technology development in 2018 , as defined by the number of patents issued by the USPTO. In the same year, the U.S. received $48 \%$ of patents awarded by the USPTO, with another 35\% issued to five countries (Japan, South Korea, China, Germany, and Taiwan), 9\% to seven countries (UK, India, Israel, Italy, Netherlands, Sweden, and Switzerland), and the remaining $9 \%$ of ( $~ 31,000$ patents awarded) distributed across 111 different nations.

\subsubsection{What is a Trademark or Service Mark?}

A trademark is a word, name, symbol, or device that is used in trade with goods to indicate the source of the goods and to distinguish them from the goods of others. A service mark is the same as a trademark except that it identifies and
Table 2 US patent and trademark office - patents awarded by Country—2018

\begin{tabular}{|c|c|c|c|c|c|c|}
\hline \multicolumn{7}{|l|}{ Patent types } \\
\hline Country & Utility & Design & Plant & Re-Issue & Total & $\%$ of total \\
\hline United States & 144,413 & 16,644 & 493 & 259 & 161,809 & 48 \\
\hline \multicolumn{7}{|c|}{ TIER 1 [ >10,000 patents awarded] } \\
\hline Japan & 47,566 & 2014 & 43 & 79 & 49,702 & 15 \\
\hline South Korea & 19,780 & 1967 & 7 & 63 & 21,817 & 6 \\
\hline China & 15,224 & 2520 & 5 & 5 & 17,754 & 5 \\
\hline Germany & 16,033 & 1196 & 81 & 16 & 17,326 & 5 \\
\hline Taiwan & 10,933 & 793 & - & 16 & 11,742 & 3 \\
\hline Sub-total & 109,536 & 8490 & 136 & 179 & 118,341 & 35 \\
\hline
\end{tabular}

TIER 2 [2000 to 9999 patents awarded]

\begin{tabular}{l|r|r|l|l|r|r}
\hline United Kingdom & 6616 & 943 & 27 & 13 & 7599 & 2 \\
\hline India & 4225 & 103 & - & 1 & 4329 & 1 \\
\hline Israel & 3996 & 191 & 28 & 4 & 4219 & 1 \\
\hline Italy & 2802 & 557 & 24 & 3 & 3386 & 1 \\
\hline Netherlands & 2700 & 200 & 317 & 3 & 3220 & 1 \\
\hline Sweden & 2807 & 359 & - & 11 & 3177 & 1 \\
\hline Switzerland & 2669 & 312 & - & 6 & 2987 & 1 \\
\hline Sub-total & 25,815 & 2665 & 396 & 41 & 28,917 & 9 \\
\hline TIER 3 [<2000 patents awarded] & 27,996 & 2,698 & 183 & 49 & 30,926 & 9 \\
\hline Total Non-U.S & 163,347 & 13,853 & 715 & 269 & 178,184 & 52 \\
\hline Total & 307,760 & 30,497 & 1208 & 528 & 339,993 & 100 \\
\hline Adapted from & & & & & &
\end{tabular}

Adapted from [3, 6] 
distinguishes the source of a service rather than a product [4]. Trademark rights may be used to prevent others from using a confusingly similar mark, but not to prevent others from making the same goods or from selling the same goods or services under a clearly different mark.

\subsubsection{What is a Copyright?}

Copyright is a form of protection provided to the authors of "original works of authorship" including literary, dramatic, musical, artistic, and certain other intellectual works, both published and unpublished. In the U.S., the 1976 Copyright Act generally gives the owner of copyright the exclusive right to reproduce the copyrighted work, to prepare derivative works, to distribute copies, to perform, or to display the copyrighted work publicly [4].

\subsection{Summary}

- Technology transfer (tech transfer) is the process of transferring (disseminating) technology from a person or organization that owns or holds it to another person or organization. The goal for tech transfer is to bring new discoveries, either individually or collectively, to market by creating a product or service.

- A significant driver of tech transfer in the U.S. and globally was the framework provided by the Bayh-Dole Act, as it has become known, which defined a uniform patent policy among the governmental agencies that funded research, enabling universities, non-profit organizations, and for-profit businesses to retain ownership of their discoveries. Many countries have adopted similar regulations since the Act was approved in 1980.

- To ensure that an inventor or researcher, and their institution, can benefit from their discoveries and, in turn, ensure that the idea is moved to its full realization and commercialization for the benefit of the larger society, it is critical that there be a robust regulatory and legal framework that protects these ideas, including patents, copyrights, trademarks, and licensing.

\section{The Potential of Tech Transfer for Universities}

\subsection{The Impact of University-Based Tech Transfer}

To understand and fully grasp the power of university-based tech transfer, one needs only consider the following facts regarding long-term impact of research and innovation on the U. S. economy:
- From 1980 to 2013, more than 5,000 startups were created through university tech transfer programs [7].

- From 1996 to 2013, tech transfer has enabled \$518 Billion to the U.S. Gross Domestic Product (GDP) on \$1.1 Trillion on the U. S. Gross industrial output [7].

- During this same 17-year period, 3.8 MM jobs were added to the U. S. economy [7].

A recent survey by Association of University Technology Managers (AUTM) [8] of 198 U.S. universities noted that these research institutions posted a record number of patents in 2018. For the second year in a row, Technology Transfer Offices (TTOs) in this group of institutions formed 1,080 start-ups. In 2018, these institutions of higher education produced 828 new consumer products coming from academic research entered the market, and 7625 US patents were issued. This is the most-ever reported in the survey.

Total research expenditures from sources outside the federal government and industry grew to $\$ 71.7$ billion, an increase of $5.1 \%$ over 2017 , and a $13.8 \%$ increase over the past five years. Investments and growth that directly impacted local economies, with more than $69 \%$ of the new businesses remaining in their institution's home state. This underscores the importance of tech transfer on local economies, none of which would have been possible without the regulatory framework defined in the original Bayh-Dole Act.

\subsection{Technology Transfer Across Industries}

\subsubsection{Types of Technology Transfer}

It is not only about medicine and engineering discoveries. According to the USPTO, patents were filed for new IP across 30-different categories or classifications. Table 3 provides a list, demonstrating the wide range of potential new products being introduced into the market [9].

The table amply demonstrates that opportunities exist for capturing IP rights associated with new discoveries across a wide range of disciplines. From a university perspective, this illustrates the importance of taking a holistic approach when working with university faculty. Any department pursuing research can be a source of IP and yield an opportunity to eventually realize both academic and economic goals. The question to consider is in what industries are the opportunities most significant to translate their academic research into a transaction that will produce both social and economic benefits.

\subsubsection{Identifying Market Opportunity}

One way to examine how different industries have responded to the introduction of new products and services is to look at the number of transactions or licensing agreements occurring across industries. According to the ktMINE 
Table 3 US patent and trademark office - summary of major categories of patents

\begin{tabular}{l|l|l|l}
\hline Food & $\begin{array}{l}\text { Resin, synthetic rubber, } \\
\text { artificial \& synthetic fibers }\end{array}$ & Machinery & $\begin{array}{l}\text { Motor vehicles, } \\
\text { trailers, parts }\end{array}$ \\
\hline $\begin{array}{l}\text { Beverage \& } \\
\text { tobacco }\end{array}$ & $\begin{array}{l}\text { Pharmaceuticals \& } \\
\text { medicines }\end{array}$ & Computer \& electronic products & $\begin{array}{l}\text { Aerospace } \\
\text { product \& parts }\end{array}$ \\
\hline $\begin{array}{l}\text { Textiles, apparel, } \\
\text { leather }\end{array}$ & $\begin{array}{l}\text { Other chemical products \& } \\
\text { preparations }\end{array}$ & $\begin{array}{l}\text { Computer and peripheral } \\
\text { equipment }\end{array}$ & $\begin{array}{l}\text { Other } \\
\text { transportation } \\
\text { equipment }\end{array}$ \\
\hline Wood products & Plastics \& rubber products & Communications equipment & $\begin{array}{l}\text { Furniture \& } \\
\text { related products }\end{array}$ \\
\hline $\begin{array}{l}\text { Paper, printing \& } \\
\text { support activities }\end{array}$ & $\begin{array}{l}\text { Non-metallic mineral } \\
\text { products }\end{array}$ & $\begin{array}{l}\text { Semiconductors \& other } \\
\text { electronic components }\end{array}$ & $\begin{array}{l}\text { Miscellaneous } \\
\text { manufacturing }\end{array}$ \\
\hline Chemicals & Primary metal & $\begin{array}{l}\text { Navigational, measuring, } \\
\text { electromedical, control } \\
\text { instruments }\end{array}$ & $\begin{array}{l}\text { Medical } \\
\text { equipment \& } \\
\text { supplies }\end{array}$ \\
\hline Basic chemicals & Fabricated metal products & Transportation equipment & $\begin{array}{l}\text { Other } \\
\text { miscellaneous }\end{array}$ \\
\hline Adapted from & & &
\end{tabular}

Adapted from [9] database [10], the bulk of licensing agreements are occurring in a handful of industries. In 2007, five industries accounted for $46 \%$ of all transactions, whereas in 2016, they accounted for $55 \%$ of the total (Fig. 1).

Most industries appear to have weathered the effects of the Great Recession of 2007-2009. From 2007 to 2016, changes occurred in the distribution of business transactions across six major industries.

- In 2007 business services accounted for the largest percent of business transactions $(\sim 13 \%)$. By 2016, this had declined to $\sim 10 \%$.
- Consumer products reported the most significant decline, from $\sim 8 \%$ in 2007 to $\sim 5 \%$ in 2016.

- The three healthcare-related sectors (i.e. biotechnology, healthcare-pharmacy, and healthcare-products) experienced the most significant collective increase, from $21 \%$ in 2007 to $36 \%$ in 2016.

For universities with medical schools and programs that train and pursue research in these disciplines, it points to an opportunity that is already well defined. The current COVID-19 pandemic will only serve to increase this area of demand.

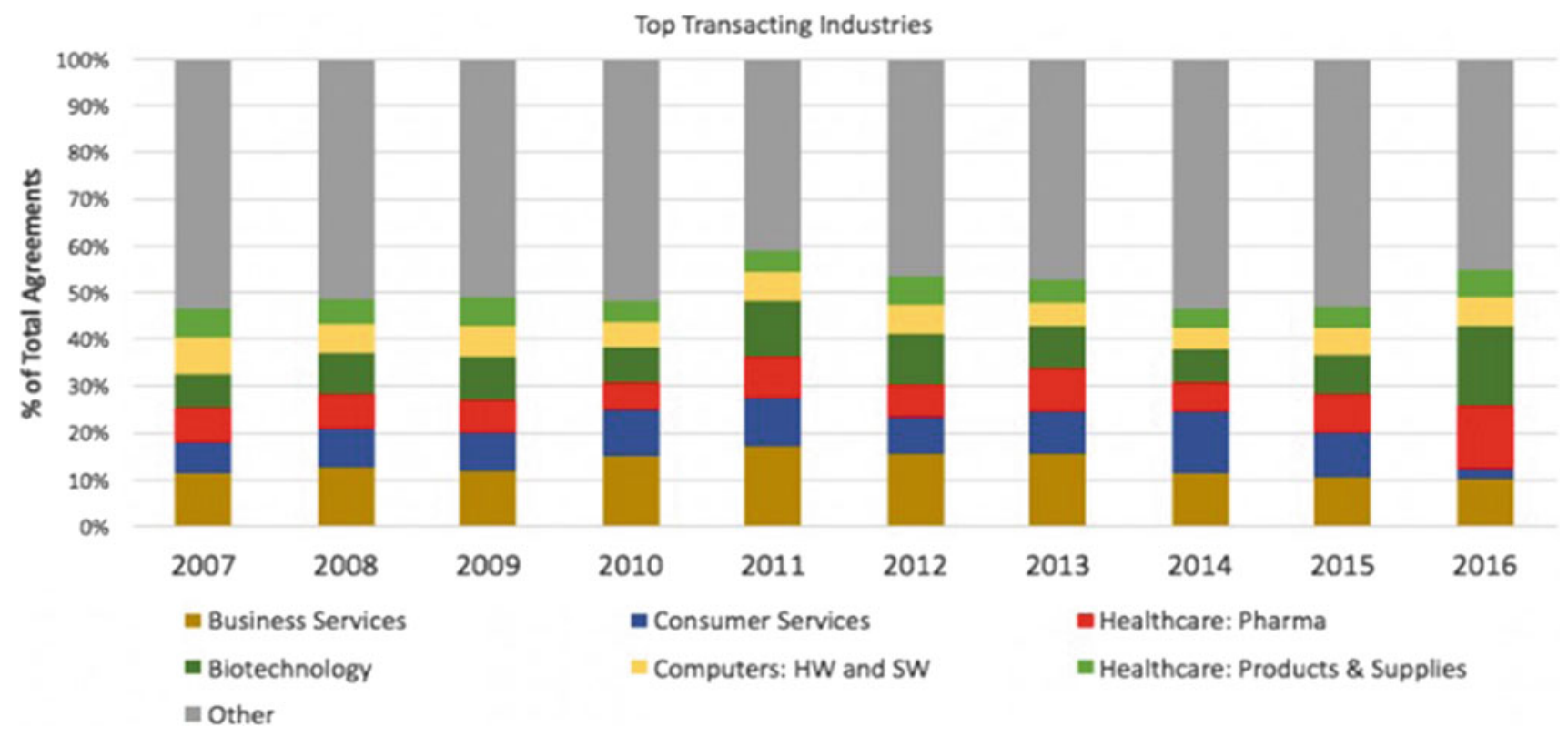

Fig. 1 IP licensing transactions by industry-2007 to 2016 (from [10]) 


\subsection{Mechanisms for Translating New IP Into Products for The Market: 1980 to Now}

When the Bayh-Dole legislation was initiated in 1980, the prevailing focus was on protecting discoveries and then seeking opportunities to license that IP to large established companies. The term "entrepreneurship" was barely understood. There was a "one size fits all mentality" when it came to commercialization of new discoveries. Few mechanisms were available to universities through which to move their nascent technology into the market. In those early days, university TTOs were focused on four priorities: (1) educating faculty about tech transfer; (2) seeking to identify new patentable discoveries coming out the faculty's labs; (3) filing patents; and (4) identifying licensing partners. Breakthrough discoveries were surrendered by universities to corporations for limited payments and modest royalty agreements across all industries from information technologies to materials to drugs and medical devices.

However, in the last 20 years the world of tech transfer and IP has changed dramatically. While these four fundamental functions of TTOs remain important, new opportunities for financing discoveries have evolved and investigators have uncovered the value of promoting their own work and, thus, of entrepreneurship. These changes have occurred for several important reasons, as we briefly summarize below.

\subsubsection{New Systems and Technologies}

The introduction of new technologies and systems to allow for self-funding of product development and market entry. This evolution has enabled individual inventors to pursue innovation without dependence on large corporations as the only point of entry into the market.

\subsubsection{Financial Need}

As the cost of operation continues to rise, and extramural funding ebbs and flows, universities and individual investigators have come to realize that their ability to explore and create cannot remain strictly dependent upon government agencies and foundations.

\subsubsection{Investment}

Different sources of investment capital have emerged during the past 20 years. From traditional venture funding to crowdfunding, there is a novel range of opportunities enabling innovative investigators and universities to bring new ideas into the market.

\subsubsection{Laws and Policies}

As the market has matured, so too has case law regarding patent protection and the application of international business practices which have favored individual inventors.

\subsubsection{Government Programs}

In the U.S., government agencies like the National Institutes of Health (NIH), have also stepped in to enable university investigators to more readily identify funding to support their entrepreneurship in concert with their research. Two examples of this are the Small Business Innovation Research (SBIR) and the Small Business Technology Transfer (STTR) grants of the NIH. These programs are in response to the U. S. Congress' requirement that eligible governmental agencies set aside a percentage of their extramural budget so that domestic small businesses can engage in research and development $(\mathrm{R} \& \mathrm{D})$ that has strong potential for technology commercialization. These are just a few examples of an active government supporting innovation and entrepreneurship.

\subsection{Summary}

- Tech transfer can occur in virtually every field of study or discipline.

- University TTOs generally focus on four priorities: (1) educating faculty about tech transfer; (2) seeking to identify new patentable discoveries coming out the faculty's labs; (3) filing patents; and (4) identifying licensing partners.

- In the last 20 years the world of tech transfer and IP has changed dramatically with new opportunities for financing discoveries and with the greater engagement of investigators in promoting their own work and in their own entrepreneurship.

\section{Tech Transfer on Campus-From Licensing to Entrepreneurship}

\subsection{The Entrepreneurial Ecosystem}

Success breeds and encourages more success. As the marketplace observes individual scientist - entrepreneurs finding success, this encourages others to pursue innovation. The net result of these changes and conditions has been the development of an entrepreneurial ecosystem that facilitates innovation and commercialization.

The entrepreneurial ecosystem is defined by three separate but co-dependent engines, which enable successful innovation (Fig. 2). Each of the three engines (discovery, enablement, and economic development) that follow produces the fuel required to support the operation of the one that follows. 


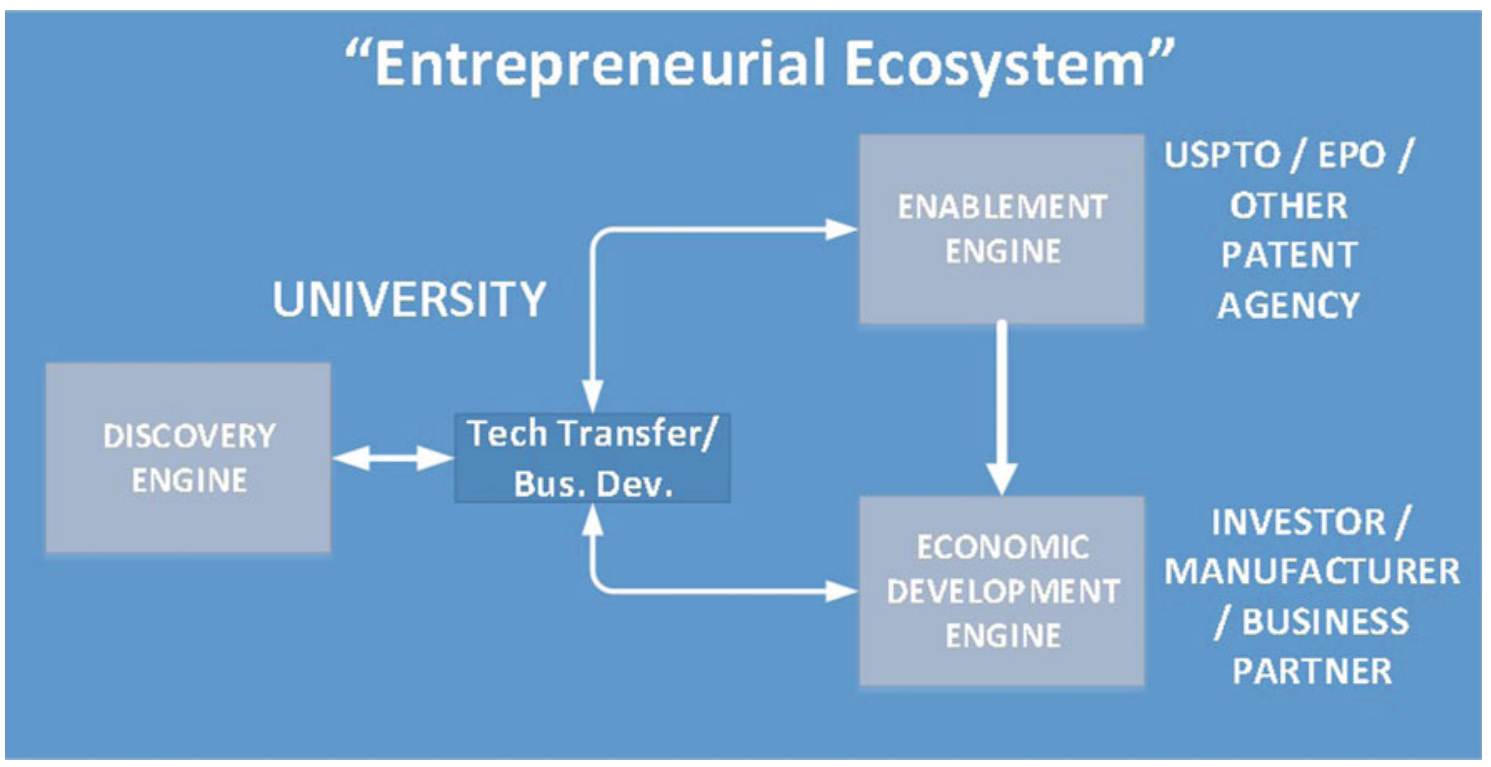

Fig. 2 The graph depicts a model representing the global ecosystem which has evolved over the past 20 years

\subsubsection{Discovery}

While there are no rules on where innovation and discovery can take place, complex problems require the best minds working together in a collaborative environment. Universities, research institutes, and academic medical centers represent the best opportunities to pool talent, as a way of testing and ensuring concepts are proven. This in turn promotes higher quality of research that can be captured, properly documented, and protected.

\subsubsection{Enablement}

This is where we see the power of effective government policy, laws, and a system of enforcement to enable individual and group entrepreneurship. Starting with the principles of the Bayh-Dole Act as exercised through organizations like the USPTO or similar structures such as the European Patent Office (EPO) or other similar agencies, discoveries can be turned into protected IP. This IP is now able to fuel the third engine, economic development.

\subsubsection{Economic Development}

Of the three engines of the 'Entrepreneurial Ecosystem', economic develop has evolved the most during the past 20 years. While private investment through venture funds has been in place since the 1990s, new financing vehicles have been identified. Moreover, international trade agreements, cooperative legal systems regarding IP, and the ability to communicate through the internet, have all played significant roles in expanding the opportunities of individuals and universities to secure economic development opportunities.

\subsection{Developing a System of Tech Transfer in a University: Fueling the 'Discovery Engine'}

The Association of Public and Land-grant Universities (APLU) is a U.S. research, policy, and advocacy organization of public research universities, land-grant institutions, state university systems, and higher education organizations. With a membership that consists of 246 public research universities in the U.S., Canada, and Mexico, the APLU advocates for public policy to enable innovation on university campuses. The APLU supports the idea that innovation drives our economy and improves the health and quality of life for people, by incentivizing discoveries and moving good ideas to full development and commercialization. To this end, the APLU established the Task Force on Managing University Intellectual Property to examine the purposes of university innovation, technology transfer, commercialization, and entrepreneurship. In 2015, the task force released a statement of recommendations on reaffirming and communicating the purposes of university management of IP. The following summarizes these recommendations for university leaders [11].

- University leaders should follow the recommendation of the National Research Council's 2011 report, "Managing University Intellectual Property in the Public Interest", to create a clear university IP policy.

- University leaders should identify existing institutional policies that restrict the university from working with 
organizations acquiring IP rights without the intention of commercialization.

- University leaders should identify and implement approaches that effectively manage university IP, and more broadly to engage with other entrepreneurs and/or industry, emulating practices that have been effectively adopted by peers.

- University leaders should develop a framework for assessing IP practice to include multiple measures that capture and reflect the university's IP management mission.

Figure 3 depicts a generic university operating in a traditional department-based academic research model. Each department (e.g. biology, engineering, information technology, botany, physics, literature, etc.) have some level of peer-review funded research. Each department also has a department head or chair, and likely vice chairs, with responsibility over research, teaching, business operations, and other support functions. Likely, there are many other layers (university administration, academic or faculty senate, etc.) defining overall university operations and in turn the academic focus of these institutions. Each chair is responsible for defining the academic direction of their department, its business operations, allocation of available resources and ensuring adequate resources are available to achieve the desired growth and development [11].

The departmental model of academia today, centered as it is around specific self-defined disciplines, fosters the development of, often intractable, siloes. However, today's model for research, its 'Discovery Engine', should be built on a chassis of teamwork and collaboration. Since most problems being studied are complex, success occur most frequently when multidisciplinary teams that integrate different departments can coalesce and bring together a broader range of idea and problem-solving skills. Furthermore, effective research often involves collaboration with teams from different universities, institutions, and countries.

External collaborations can also include companies who themselves have their own $R \& D$ teams. In recent years, many large companies that traditionally had internal $R \& D$ units have abandoned them in favor of seeking the work of external universities and research institutes. As the APLU guidelines note, innovation and entrepreneurship require highly visible support from university administration and leadership. This support comes in several forms:

\subsubsection{Cultural Balance}

For universities, the challenge of establishing the appropriate balance between the demands of a traditional academic system that demands peer-review publications as a yardstick of excellence and more entrepreneurial pursuits. University leadership needs to determine that balance and provide permission for faculty to pursue either as their interests direct them.

\subsubsection{Support for Collaborations and Partnerships}

Policies that encourage, enable, and facilitate collaboration both within the university, across departmental lines, and with outside organizations and companies are vital. This could include support for both formal and informal channels of communications where the work of investigators is made available across departments.

Fostering internal collaboration and innovation also may involve the development of cross/multidisciplinary institutes or centers in universities. These may include not only internal members but also external members, from other universities, research institutes or companies. While the development of these university-wide units seems logical, they often run afoul of faculty's own departmental-based view of what an academic discipline is. Hence, establishing and growing these cross-disciplinary units requires significant and visible leadership support as well as meaningful seed funding and other resource allocation. Otherwise, they may simply become a focus of faculty discontent, rather than of collaboration and invention.

\subsubsection{Financial Incentives}

These are defined by policy that rewards individual investigators and their teams when a patented discovery produces new IP that is licensed and commercialized. While a full discussion of the exact formula goes beyond the scope of this chapter, we should mention a few elements of importance when developing university-based tech transfer incentive plans.

\section{Develop Incentive Plans Carefully and Fairly}

Great care must be put into the development of incentive formulas or metrics. University leaders must recognize that university faculty and researchers are extraordinarily aware (over-aware) of their own skills and needs, while simultaneously often not understanding or even undervaluing the contributions of the institution to their own success. Hence, formulas that somehow are viewed as being punitive, unfair, or stingy to individual investigators will have the counter-effect of suppressing invention, the sharing of ideas, and entrepreneurship. Institutional leaders should remember that most inventions will yield small amounts of royalty, if at all. Consequently, they should strive to incentivize greater numbers of discoveries and successful faculty, rather than trying to maximize the institution's take on any individual discoveries. For example, institutions may consider tiering incentives, such that more goes to the investigators when 


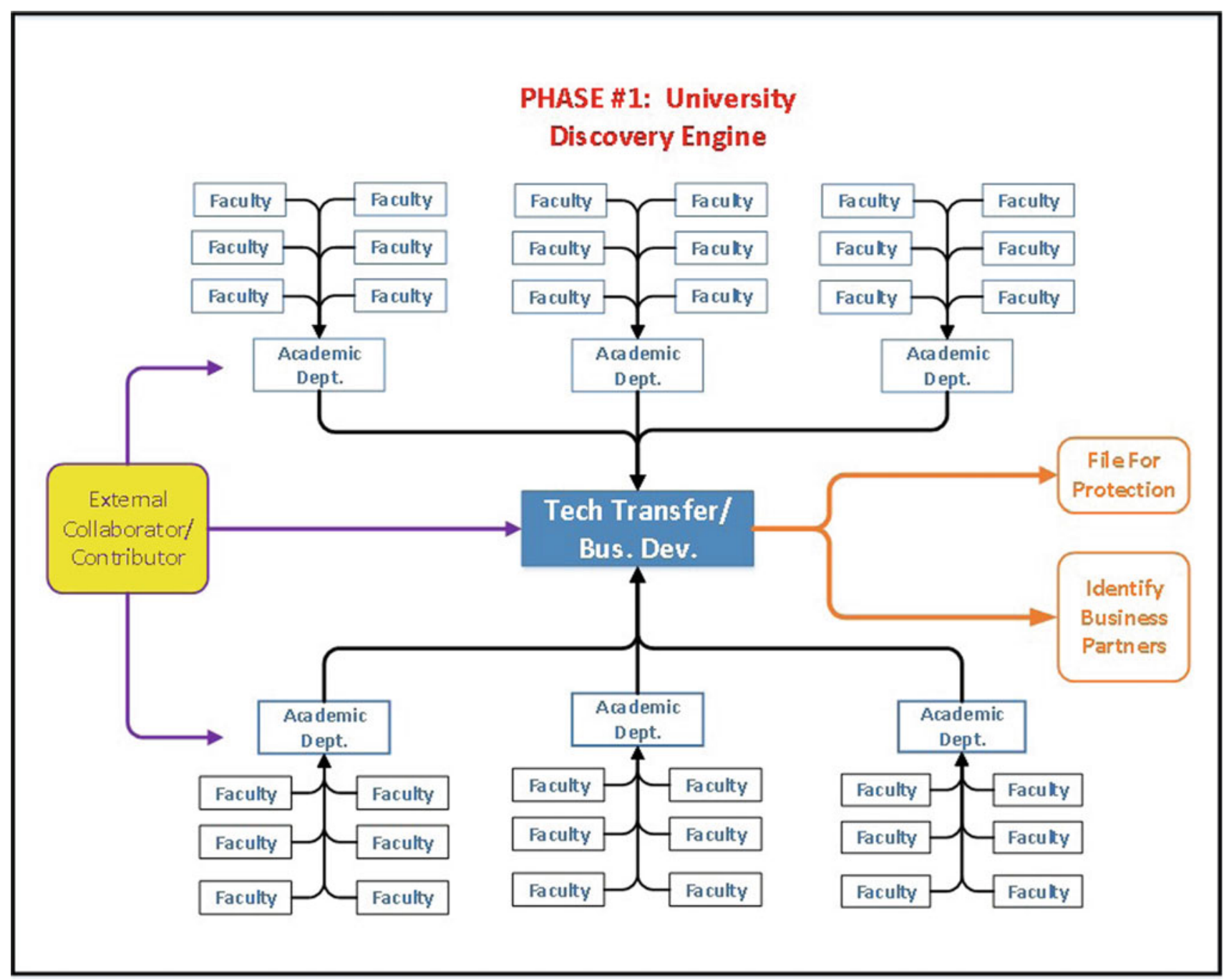

Fig. 3 The first engine of the entrepreneurial ecosystem - The university discovery engine

royalties are lower and the proportion that goes to the institution increases as the total royalties increase.

\section{Be Transparent}

Keep metrics simple and easily understood. Anything that is complex will be viewed with suspicion and negativity. And be clear where the monies obtained by the institution go.

\section{Incentivize Individuals and Teams}

Find ways to ensure the productivity and loyalty of those investigators who are the principal drivers (i.e. dealmakers or rainmakers), but also to separately incentive teams. Furthermore, consider incentivizing in some fashion the TTO or management teams that enable these deals occur.

\section{One Size Does Not Fit All}

As institutions and institutional culture varies widely, one size does not fit all when it comes to incentive plans. Each institution should work transparently with their faculty to establish such metrics and incentive formulas.

\section{You Get What You Incentivize}

Often forgotten when designing an incentive plan is the propensity for these to have unexpected consequences. It is important to carefully understand how the incentive plan may work out in the university ecosystem. As you create monetary incentives in one direction, leaders should not be surprised when faculty then focus on those areas, often to excess and possibly at the expense of other important activities (e.g. research instead of education).

\subsubsection{Supportive Physical Environment}

Collaborative research often depends upon physical space that enables what is referred to as points of intersection or collision when investigators can meet and exchange ideas. This means having proper conference space for formal 
meetings and open more causal spaces which promote informal discussions. These informal discussions often lead to productive exchange of ideas when promotes more formal working relationships.

\subsubsection{Business Infrastructure}

TTOs employ trained professionals to support the discovery pipeline. If operating effectively, the office provides a nexus for all of the business-related activities required to move science out of the lab and eventually into the market. These offices enable the movement of data, samples, and information from outside the university to the appropriate investigator supporting the research and ensuring all sides are protected. TTOs help identify when a new idea is ready to be turned into an invention disclosure or when it is too early to capture ideas that warrant the protection that creates IP. There are standard documents and agreements that provide the basic infrastructure by which, TTOs receive and manage information that flows through their domain.

\section{Material Transfer Agreements (MTAs)}

MTAs are used to document in the transfer of materials [i.e. cell lines, tissue, materials, or compounds, etc.] into a university and/or research lab from another university. The objective is to define ownership of the materials that will be introduced to enable results in other research activities.

\section{Confidentiality Agreements (CDAs)}

CDAs are used at the initial stages of conversation between two organizations each wishing to share information and begin a process of negotiation, leading to an eventual transaction. The CDA protects each company's rights to privacy vis-à-vis confidential information that may need to be disclosed by either party to the other to initiate a transaction.

\section{Data Use Agreements (DUAs)}

DUAs are used to allow the flow of proprietary data and information between two entities. These entities could include two university research programs wishing to share information to advance science or between a university and private company also seeking to advance research towards new technology.

\section{Invention Disclosures (IDs)}

IDs are filed by the investigator with the TTO and represent the first codification of the discovery. This becomes the document of record if/or when there is a filing with the patent office. It is used to describe the essence of the discovery that is to be filed and ultimately becomes a patent or other type of IP.

\subsubsection{Establishing Technology Transfer Offices (TTOs)}

Today, most universities with active research programs have introduced and funded a TTO. The problem most offices face is that all too often results are mixed and fail to demonstrate an anticipated value when evaluated by their university leadership. When expectations appear to have not been met, it is likely due to three fundamental misunderstandings regarding what can and should be expected of these offices.

The mission of university based TTOs is often misunderstood by university administration and the investigators they have been asked to support. TTOs are in place to facilitate, support, and ensure compliance with the processes around invention and commercialization. They do not drive commercialization or revenue generation directly.

Expectations placed on these offices and what they can realistically accomplish vis-à-vis new business development is often not aligned with the realities of the market. Expectations can also become distorted around the idea that these offices will generate huge financial returns every year.

The wrong metrics are often applied to how these offices are evaluated [12]. For example, the number of times an invention disclosure or MTA is completed cannot and should not be used as any measure of a TTO's effectiveness. The best measure of success for any TTO should be based on whether the following are in place:

- Support of and information for the entire community of university investigators.

- Rapid and efficient service to investigators and to external partners, regulatory agencies, funders, and commercial interests.

- Capabilities are available to assess new technologies, provide a fair and accurate assessment of how novel they are, and the opportunity offered to protect and generate market relevant IP.

- A network of contacts and professionals is available to provide the skills, knowledge, and experience to create a system for filling patent claims and identifying opportunities to bring these discoveries into the market.

\subsection{Summary}

- During the past 20-years, an "Entrepreneurial Eco-System" has evolved that is structured around three fundamental engines or sub-systems: (1) discovery, (2) enablement, and (3) economic development.

- The most direct road to success comes when universities fully embrace processes that proactively protect new 
discoveries made by their research faculty, by actively capturing new IP.

- Research and the path to successful entrepreneurship is only possible when viewed by all involved as a "team sport". A wide range of skills and experience is required from a multi-disciplinary team.

- A culture that embraces entrepreneurship is also critical to long-term success. This culture needs to find a balance between traditional academic demands such as the importance of peer reviewed publications against a commitment to planning, budgeting, and sound business management.

- Positive and productive partnerships between universities and industry is also critical. If structured correctly and with the right incentives, it can significantly increase the chances of success for new technology being introduced into the market.

- University TTOs can play a pivotal role in the process of bringing new technology out of a university lab and into the market. The TTO should be developed with appropriate resources to manage this complex process. The TTO manages the business side of entrepreneurship, enabling researchers to do what they do best; that is making groundbreaking discoveries.

\section{Bridging the Gap Between Innovation and Commercialization}

\subsection{Fueling the 'Enablement Engine'}

The process of creating or enabling IP by filing for a patent or some other type of protection is well defined. The challenge with filing for IP protection is two-fold: (1) the time required can be significant (on average 3 years), and (2) the costs associated with the process can become significant. The process can also be unpredictable and produce delays that are difficult to resolve. Figure 4 provides a view of the process and average time spans associated with submitting and prosecuting a patent application. We will use the experience with the USPTO to illustrate the basic steps of the process, as described below:

\subsubsection{Novelty Search}

This is among the 1st steps in the process. While optional, it is important to ascertain if in fact others have already filed similar ideas [a.k.a. defined as "prior art"]. This will provide guidance as to whether the certifying agency (i.e. USPTO) will grant a patent and how broad those claims might be.

\subsubsection{Filing the Application}

The next step generally requires from 4 to 6 weeks to complete. The patent application can be filed as provisional or non-provisional. The provisional application establishes a "place in the line" which is good for 12 months following the date on which it was filed. Though not reflected in Fig. 4, during this year it is advisable for the TTO to initiate a process of testing the market for potential licensors or to explore funding to take the IP forward into product design, development, and commercialization.

\subsubsection{Examination}

At the conclusion of the year, a non-provisional application is issued and there is a claim back to the date at which the provisional patent was filed. Note, once filed as a provisional the patent is noted as "pending". The advantage for inventor and the university of having a "patent pending" is that others are barred from filing and securing patent protection on a similar discovery. Post filing, a period of $1-3$ years begins during which time the USPTO evaluates or examines the claims in the patent application. Steps can be taken at the time when the application is filed to shorten the standard wait time for office actions. A fee can be paid to obtain a prioritized office action which can reduce the time to as little as 6 months. Working in concert with the investigator, the TTO can guide this process [13].

\subsubsection{Office Actions}

Acceptance or rejection of the application is provided through office actions According to USPTO statistics, approximately $90 \%$ of all applications receive a rejection on the initial application. The process strives for balance between granting claims that are broad enough to provide reasonable value and prevent infringement but at the same time prevent intersection of these claims with any prior art that is identified. This process can occur numerous times and with each re-submission costs ranging from hundreds to thousands of dollars are incurred. The university, in consultation with the investigator and the TTO need to focus their strategy on managing this process. At some point, there could be a realization that the cost of securing the patent could nullify or render the potential patent(s) unable to achieve a reasonable return on investment.

\subsubsection{Issuance, Appeal, Abandonment}

At this final stage, the USPTO will either issue a patent or not. The issued patent may only cover limited or narrow claims as compared to what was initially submitted. At that point, it is up the organization that filed the patents to accept the claims as issued, file an appeal or simple abandon the filling. At any point in this process the filing organization can decide to abandon their filing. Once the patent is issued 


\section{Patent Process}

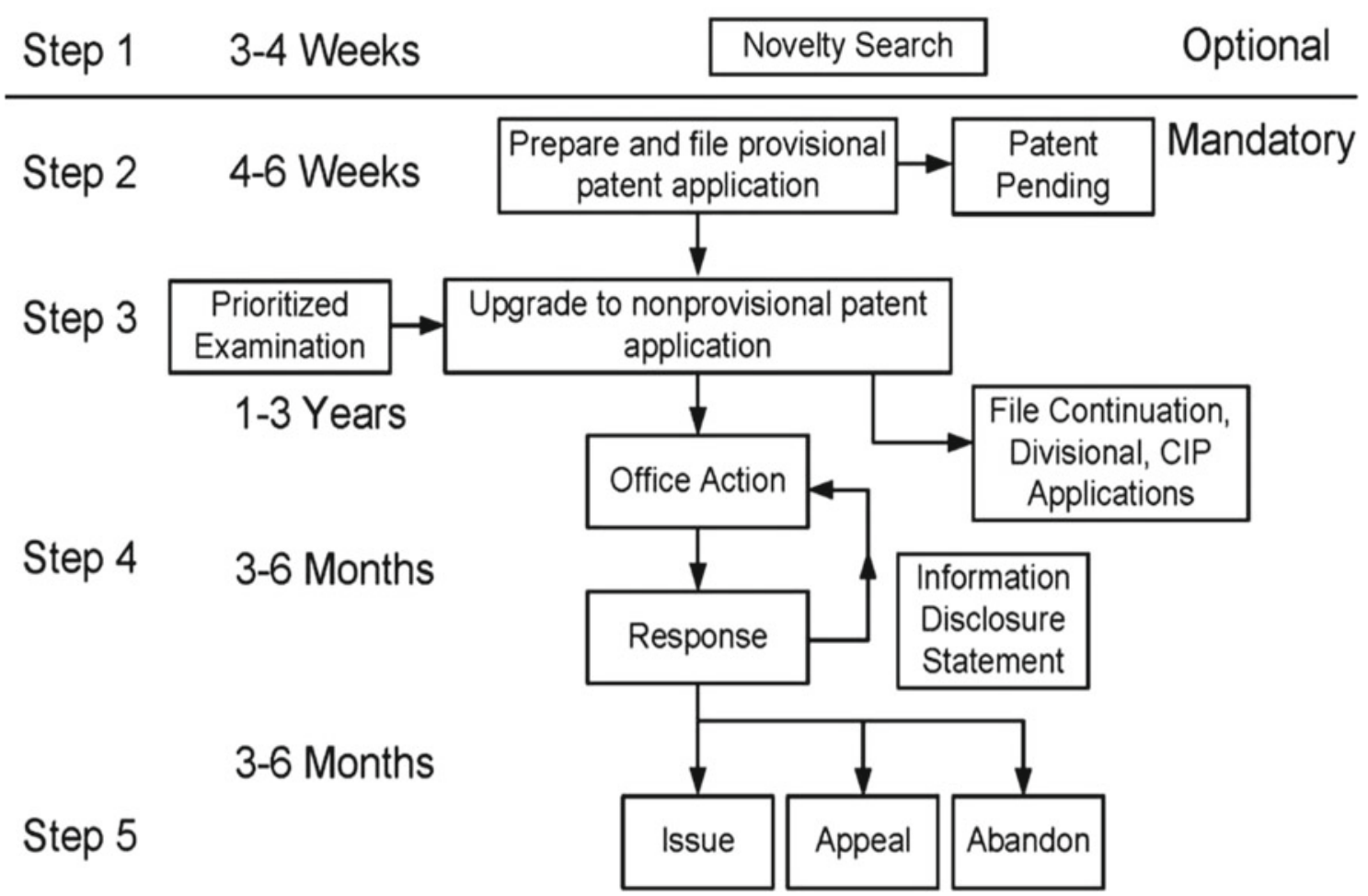

Fig. 4 The second engine of the entrepreneurial ecosystem-The enablement engine (from [13])

maintenance fees come due at 3 years and 6 months, 7 years and 6 months, and 11 years and 6 months.

As mentioned before, before entering the patent process, analysis of patentability is critical. It is also vital to know in which jurisdictions to pursue patent protection. The USPTO only provides patent protection in the U.S. and its territories. Decisions should be made upfront regarding which other countries to seek patent protection. This should be driven by what the IP is for, its market potential if converted into a product, and the resources available to support the process. Patent related expenses will increase exponentially, if further protection is pursued through the WIPO, EPO, and in other countries in Asia and South America. This is where the patent assessment referred to above and a market analysis, discussed in the section that follows, will be instructive towards making these strategic decisions.

\subsection{Mechanisms for Disseminating and Commercializing Technology and IP- Fueling the 'Economic Development' Engine}

While the processes associated with the 'Enablement Engine' are generally well established, the operational dynamics that drive the 'Economic Development Engine' continue to evolve. The process of identifying a licensing partner is essentially the same and is also generally well defined. The challenge is understanding the true value of the IP and finding a licensing partner who is willing to provide appropriate compensation by way of initial licensing fees, milestone payments and ultimately a reasonable royalty rate. When it comes to taking a more entrepreneurial tact and developing IP into a product or service, this requires more time, money, and a willingness to accept greater risk. New approaches to funding continue to be introduced as well as variations on established forms of financing and ownership. While the tools continue to evolve, the basic goals remain unchanged:

- Speed to market with as few missteps as possible

- A nimble process capable of making adjustments as conditions evolve

- Compliance with legal and regulatory standards for wherever the country, state, or legal jurisdiction in which the business will be operating

- A well-crafted business model that ensures reasonable and equitable returns to all involved.

Above all, before launching into either process it is critical to have a firm understanding of the regarding the 
potential need and demand of the market for what the technology can provide to consumers. When pursuing a start-up, a well-conceived business plan is a critical success factor. This process should be managed by the TTO in cooperation with the investigator who knows their science best and understands its underlying potential. Regarding timing, elements of the business plan process should start in conjunction with the filing of the invention disclosure (ID). In fact, the IDs form the basis of several elements of a standard business plan. Below is an overview of basic elements of a business plan.

\subsubsection{Market Assessment}

During this process, studies are conducted to isolate who the potential consumer(s) of the product or service will be. The market analysis also helps to focus the development process so that the product or service is well understood, and the number, location and socio-demographic profile of prospective consumers is fully appreciated. The study allows an opportunity to test the market for potentially competing products or services, understand or define a process for marketing and branding, and how these ideas will be accepted into the market. Finally, it forms the basis for determining potential pricing strategies and defining volume forecasts that will drive the eventual accumulation of revenue.

\subsubsection{Intellectual Property (IP) Summary}

The invention disclosure provides the foundation for this component of the business plan. Once the patents have been filed [provisional of non-provisional] there is now some sense of what the IP can offer to prospective investors. This may change over time as office actions are returned and the range and depth of patent claims are better understood.

\subsubsection{Proforma}

The proforma provides the basis of any request for funding support in exchange for ownership. It defines the total investment required, the timeline for product development, market entry and scaling up of sales through the ultimate financial return on the investment(s). The proforma consists of three essential components:

\section{Revenue Model}

This model brings together information captured in the market assessment and converts those findings into a projection of future revenues. The model is driven by three factors. First, a market assessment that defines the potential demand (i.e. units of service) that the market is likely to require. The market assessment should also provide an unbiased understanding of how to price whatever it is that is being produced and sold. Finally, the pace for product/service absorption by the market also needs to be considered. This latter parameter will have a major impact on how the operating expense budget is defined and therefore the funds required to support company start-up.

\section{Operating Expense Model}

This model determines how much of an investment will be required to achieve a positive operating position, payback on the investment and future return on investment (ROI). The model is determined by several basic components. First, is an understanding of the staffing required to support the start-up. In this analysis, the number of people required, skills and experience of the staff, what will be done by internal staff versus consultants, the pace of development, etc. is all considered. In addition, basic operating expenses need to be considered such as the cost of space (e.g. rent), office operating expenses, travel related expenses, cost to support the patent process, marketing and any other fees associated with day-to-day operation of the new venture need to be identified. In addition, the proforma will need to include things like interest and depreciation on capital investments that are required. In total this analysis provides a full operating expense statement that is incorporated into the proforma, or operating profit and loss statement.

\section{Capital Budget}

In general any physical asset greater than $\$ 5000$ can be considered as capital and budgeted as such. From a cash flow perspective an understanding of this is critical. These assets require cash for purchase but under the right circumstances the annual depreciation of the items is added into the operating profit and loss statement.

\subsubsection{Implementation Timeline}

Among the more important elements of any business plan is an implementation timeline or "critical path". This outlines the process from start-up through the new company reaching a full operational status. This timeline provides an overview of major milestones that need to be completed as the company is ramped-up. This is also of importance to investors who want to track progress of their investment to ensure an understanding of when they might begin to see a return on their investment.

\subsection{The 'Engine for Economic Development' at Work}

Figure 5 depicts a flow chart that defines the basic "Economic Development Engine" which represents the third and final phase of the overall Entrepreneurial Ecosystem (see also Fig. 2). It is here where results are achieved or not. The 
best discovery science accompanied by successful patenting or enablement of the science may not reach the intended market without effective execution. Up to now, much of the work is academic, meaning it is happening inside of a relatively closed system that is well understood. In this third and final phase, any protection that is provided by consistent and well understood systems if replaced by a free market that can respond in ways that can be entirely unexpected. Again, this is the reason why it is critical that there is a solid market assessment at the beginning that can support whatever direction the university and the investigator(s) elect to take when moving their discoveries forward.

This last stage of the Entrepreneurial Ecosystem will require institutions and investigators to select a path to commercialization. For example, options include licensing to an established company or starting up a new company, the latter which can include technology incubators or accelerators.

As noted in the section above, once an invention disclosure is filed by the investigator with their TTO, a market analysis should be completed. With that market assessment in-hand, the TTO can work with the investigator(s) and select a path forward for the new technology. As with most aspects of this ecosystem, the path forward is determined by a series of questions and answers which determine the final direction to be pursued. At the Step \#2 decision diamond in Fig. 5, the TTO should try and understand the following:

- Does the IP offer a real opportunity to create financial value through its introduction as a new product or service?
- Are there established companies offering similar products or services that might be interested in adding this new technology to their existing product offering?

- Are there any lessons to be learned from those companies that would inform and influence our development process?

- Is the university or the investigator interested and able to garner the financial and professional support required to effectively develop the product on their own?

- Do any faculty investigators have the desire to take this challenge on?

The answers to these and several other questions define the decision regarding pursuing a licensing agreement with an existing company or going in the direction of a start-up. If the answer is a license, then the path is clear, and a relationship can be pursued. If the decision is more entrepreneurial, starting up a new company, then the next step would be preparation of a business plan, as described above. With that business plan in-hand, there are three potential paths to follow: (1) seek enough investment capital to pursue the start-up immediately; (2) obtain minimal funding and enter an incubator program to refine your science and begin the next evolution of product and company development, or (3) bring together what you have by way of Ideas and IP if available, and enter a technology accelerator. Below we briefly described what a technology incubator and a technology accelerator are.

- What is a Technology Incubator? Incubators support the development of new business ideas by providing mentorship, business services and funding connections to

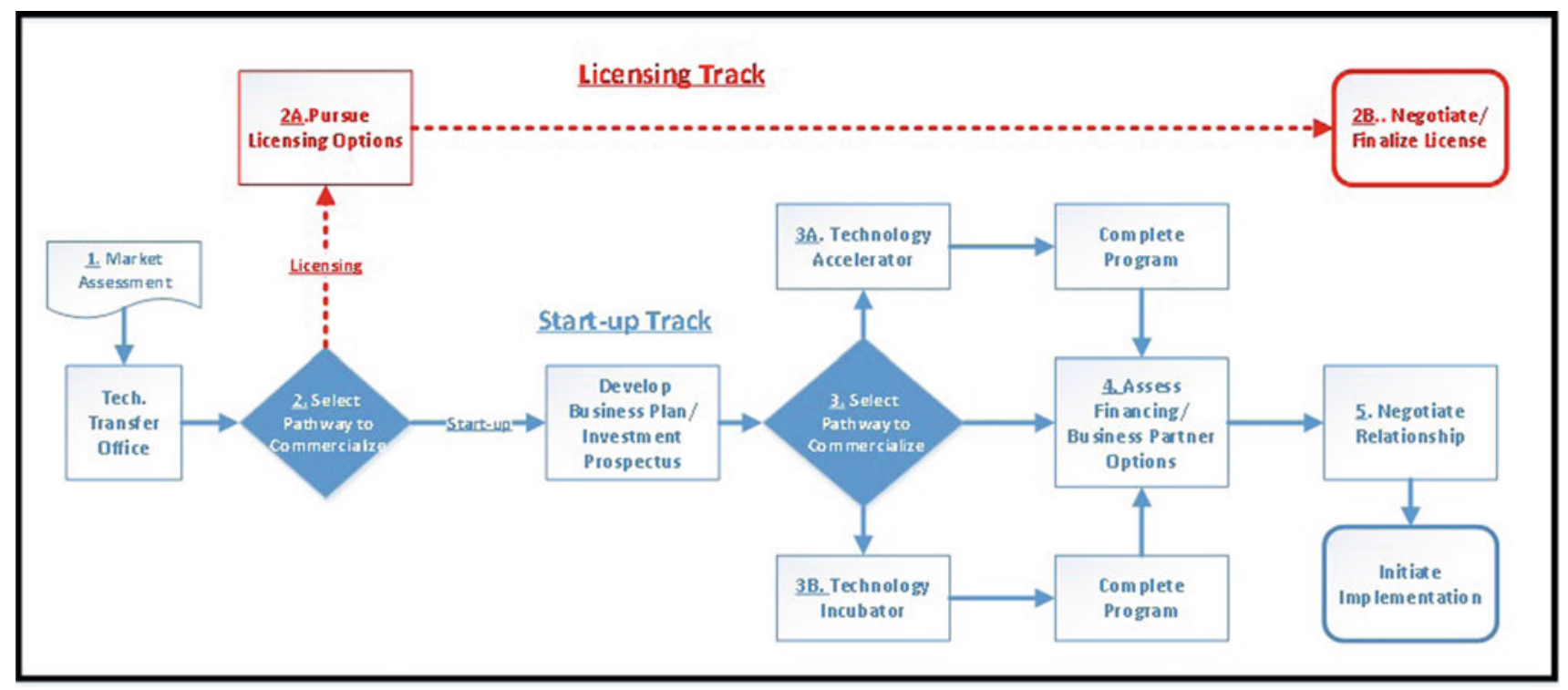

Fig. 5 The third engine of the entrepreneurial ecosystem-The economic development engine 
young tech companies. There are more than 1250 business incubators in the United States (up from 12 in 1980), and about $37 \%$ focus specifically on developing technology companies. Tech incubators come in all shapes, sizes and business models. In 2015, more than 7000 business incubators operated worldwide [14]. When the company enters into an incubator, they have some funding, a company has been established and there is a desire to utilize the mentorship and business services to position the company for its next round of funding and to move from incubation towards early stage product production and entering the market.

- What is a Technology Accelerator? Tech accelerators provide an environment in which a group of talented people or teams who have an idea for a company, receive some upfront financial support, in return for equity in the company. Similar to the incubator, the infrastructure of the accelerator provides some mentoring from people who have previous experience. In addition, office space is provided for some limited period time. The underlying goal is to try and steer people in these companies in the right direction to ensure a more successful launch. Mentors in these accelerators can come from a tech company like Google or Facebook or a venture capitalist with a track record in investing in successful startups or running their own.

Accelerators "accelerate" growth of an existing company, while incubators "incubate" ideas with the hope of building out a business model and company that can disrupt the market [15]. Once these programs (accelerator or incubator) are completed, the company should be ready to graduate to its next stage of development. Today, there is a range of options available for these university-based and faculty-driven entities to finance, productize and enter commercial markets with the discoveries. Among the options to support the ever-evolving ecosystem are the following.

\subsubsection{Licensing Agreement}

There is an expression in the patenting world that "when you have seen one licensing agreement you have seen one licensing agreement". In short, this means that each one is unique and subject to their own special terms and conditions. There are certain parameters within which most licensing agreements tend to fall:

\section{Long Term/Short Term}

In a long-term arrangement, a minimum cash payment ranging from $\$ 1$ to $\$ 1,000$ is paid upon licensing of the technology. The bulk of the value is paid to the licensor once the technology is in the market and a royalty percentage is paid. Royalties can range from $1 \%$ up to $10 \%$ but in most cases, it runs from 3 to $6 \%$ [16]. In contrast, some companies prefer to pay upfront for a cash license and secure the rights with limited if any further liabilities associated with royalty payments. In this case the payment could range up to as much as USD\$1.0M. In either case, value is determined on a case by case basis. This value is driven by several factors: (i) The stage at which the technology has been developed; (ii) market size and potential; (iii) profit margin of the potential product or service; (iv) the strength of the patent claims; (v) the cost anticipated to complete and bring the product to market, and; (vi) the nature of the license, exclusive or non-exclusive.

\section{Exclusive/Non-exclusive}

The difference between the two options is simple. Under an exclusive license only one company gets to utilize the patent rights, while under the non-exclusive multiple organizations obtain the patent rights. Exclusive licenses bring greater fees and royalty rates to the licensor, while the non-exclusive serves to mitigate risk for the licensee. Different technologies and varying patent claims as well as market conditions can drive the decision between exclusive versus non-exclusive.

It is also worth noting that different universities maintain different policies regarding the re-payment of patenting and legal fees, who they will license to, and the timing and use of milestone payments to ensure the technology is being developed. Some universities such as Caltech in California tend to pursue start-up companies when licensing their technology. They favor the start-up over larger companies and are therefore less strict regarding licensing fees and recapturing expenses associated with the patenting process. By contrast the University of California requires the licensee to repay the cost of patenting upfront as part of their standard agreement. Again, these are question's each university needs to consider as it empowers its TTO to initiate these business arrangements [16].

\subsubsection{Start-Up Companies}

During the past 25-years, more and more universities and their faculty have taken on the idea of developing their own technology via some form of start-up company. As with licensing, the approaches taken can vary widely and will often depend upon the individual universities culture, willingness to accept risk and view on the balance between commercialization and academic purity. There is no right or wrong answer but rather a set of broad decisions that need to be made by university administration before entering the market. Whatever the approach, there are mechanisms through which companies seeking start-up support can pursue. 


\section{Venture Capital (VC)}

This is a source of investment funding provided by a private equity firm capable of providing economic support to opportunities that demonstrate high growth potential. This investment comes in exchange for an equity stake in the company. Venture capital is generally available to start-up companies or smaller companies that are seeking to expand but lack the capital to elevate themselves to the next level through internal funding sources. The nature of VC investment is that it is high risk and therefore failure rates can be high. At the same time $\mathrm{VC}$ investment is designed to enable massive ROIs when the right technology is identified along with the right team leading company development.

\section{Angel Investment}

Generally associated with early stage start-up companies, an angel investor is an individual or group of individuals who provide capital for an emerging company. Angel investors are generally the first group willing to provide financial support, even ahead of more established VC firms. It is not uncommon to find angel investors among family and friends who are willing to support on a one-time basis to help get the company launched to carry the company through its most challenging phase of development.

\section{Equity Crowdfunding}

While it has been used most popularly for the funding of art and other consumer-driven causes, equity crowd-funding is still a new and evolving source of revenue by which universities can capture funds to support a range of different startups [17]. Implementing equity crowdfunding in tech transfer, a form of investing by many small investors pooling their resources, is best used for those startups that appeal to the emotion of consumers-donors (e.g. improving the lives of the disabled) and to younger individuals. Equity crowdfunding is often a useful tool for startups created by students, both to fund the development of the technology, but also as a tool to educate young entrepreneurs on how to develop their companies. An example of how this funding source is becoming mainstream is the Jumpstart Our Business Startups (JOBS) Act, signed into law in 2012 in the U.S., which allows startups to raise up to $\$ 1$ million via crowdfunding. In much the same way that universities have used their alumni to support their athletic programs, these institutions are using the commitment of this group and other supporters to develop investment funds in exchange for equity in a start-up.

\subsection{Summary}

- The evolution from a laboratory-based discovery into a product or service that can be delivered to a waiting market is complex.

- The migration from innovation to commercialization is complex and therefore proper planning is the most critical first step in what can be a long and challenging process.

- The move from innovation in the lab to commercialization into the market requires that whatever has been discovered is properly protected. This requires filing for and ultimately receiving a patent or some over form of IP protection.

- Filing for IP itself requires a strategy that takes into account the potential value of the claims being filed, the existence of prior art, a projected economic value for what the IP might produce, and the time and expense associated with the filing process.

- In conjunction with filing a patent, the larger process of moving to commercialization requires a comprehensive business plan which builds on the patent analysis but then identifies and integrates in other expenses associated with converting the discovery into a product(s) and delivering it into the market.

- This planning process helps to determine the most favorable direction to be taken: (1) licensing the discovery to an existing company, or (2) pursuing development of a start-up company that will take that discovery and produce something that the market will demand.

- If the university goes the route of pursuing a new company, there are a variety of tools and mechanisms available to support that process. This can include the use of technology incubators and/or accelerators and a host of long term and short-term options for financing the new venture.

\section{Tech Transfer on Campus-Creating the Right Culture}

A successful tech transfer program requires a change in the culture of academe - a change to make the campus more 'tech transfer friendly'. As discussed in Sect. 4.2, creating a campus culture that values, supports, and promotes tech transfer is critical to the success of the initiative and requires university-wide commitment. Creating such a campus culture begins with visible leadership, followed by engagement 
of the faculty and student bodies, ensuring the highest quality of research, and fostering and incentivizing both creativity and entrepreneurship, while recognizing that local or national cultures vary and play an important role in tech transfer. For example, not only should knowledge be valued for knowledge's own sake, but the university community should also value the ability to apply that knowledge as well.

Promotion and tenure (P\&T) reviews and academic expectations should value not only research publications, but also patents and entrepreneurial and commercialization efforts. And university leaders should recognize that while there may be individuals that drive R\&D, most successful research and tech transfer efforts today involve a team approach. This approach not only needs to be recognized, but also incentivized. We briefly elaborate.

\subsection{Visible Leadership}

A successful university-based tech transfer system begins with leadership. The changes that need to happen to the traditional culture of a university campus will require visible leadership, starting with the institution's chief executive (president, chancellor, vice-chancellor, etc.) and their team. It also will require skilled, visible, and empowered tech transfer leadership. Notably, the first recommendation of the National Research Council 2011 report, 'Managing University Intellectual Property in the Public Interest', states:

\begin{abstract}
The leadership of each institution-president, provost, and board of trustees - should articulate a clear mission for the unit responsible for IP management, convey the mission to internal and external stakeholders, and evaluate effort accordingly. The mission statement should embrace and articulate the university's foundational responsibility to support smooth and efficient processes to encourage the widest dissemination of university-generated technology for the public good. [18]
\end{abstract}

Higher education leaders should become familiar with many of the leading recommendations in the area, including the those of the National Research Council of the U.S. National Academies of Science [18], APLU [19], AAU [20], AUTM [21], and so forth. Specifically, university leaders need to be able to:

\subsubsection{Provide a Clear Vision for the Tech Transfer Initiative}

Why is it important and why does it matter? And why should individual faculty and students care? Such vision statements should be made repeatedly, clearly, concisely, and consistently. A transactional approach should be avoided when articulating this vision, and the vision should be tied not as a direct benefit to the school and faculty, but to public interest and enhanced economic development for all.

\subsubsection{Break Down Siloes}

Leaders who expect success in the tech transfer arena must be deliberate and planful in breaking down the siloes inherent in traditional academics. Many, if not most, valuable discoveries and applications arise from cross-disciplinary/multi-disciplinary efforts and collaborations, and not from the usual department-level structure inherent to traditional academics. Achieving a true cross-disciplinary model will require creating structures (e.g. institutes, laboratories, centers, etc.) that bridge across disciplines and departments. This than requires the support of academic leadership, including deans and department chairs themselves.

\subsubsection{Remove Barriers}

Leaders must also be deliberate and planful in seeking to identify barriers to tech transfer and commercialization within the university and should not wait for those barriers to become evident. There are many barriers to a successful tech transfer program, not only around campus culture, but also around support systems, client services, available expertise, networking capabilities, and so forth. Hence, leaders should proactively and continuously seek out and address the many barriers inherent to a successful tech transfer program.

\subsubsection{Provide Resources}

While no operations, particularly in higher education, ever has enough resources, it is important that leaders recognize that any transformational effort, including implementing a successful tech transfer system on campus, requires a threshold amount of resources. Resource allocation signals not importance but also prioritization. And resources are not only monetary, but also in human capital. In fact, one of the most precious resources, and one that is often not given in sufficient amount, is the attention and focus of leadership.

\subsubsection{Hire the Right Leaders}

One of the most important work of any leader is to hire and empower the right leaders. Institutional leadership should strive to hire experienced tech transfer leadership, with a focus on effective outreach and client services. They should strive to empower these individuals, not only providing them with adequate resources, but also with the necessary delegated authority.

\section{Set Appropriate Expectations}

In their zeal to provide a vision for tech transfer, one of the mistakes that leaders often make is to create exaggerated expectations. Expectations that because they are unrealistic or simply incorrect lead many on campus to quickly become disillusioned with tech transfer in general, and TTOs and their leaders in particular. It is important to note that the 
benefits of an effective tech transfer culture on campus is much more than about generating revenue for the institution. It is about driving and enhancing regional and national economic development. Additionally, the principal expectations of TTOs should be around client services and infrastructure. And because TTOs do not create the ideas and innovations, their success should not be tied strictly to royalty payments or number of inventions. Finally, a successful tech transfer program, however defined, takes time, and success should be examined in no less than 5-year intervals.

\subsubsection{Ensure Fair and Faculty-Favorable Incentives}

University leaders need to be the first to stand for fairness when monetary incentives are created for faculty. Without productive and incentivized faculty there are no inventions, discoveries, and the like.

\subsection{Engage Faculty and Students}

It is critical that the faculty be educated and supportive of tech transfer efforts. Faculty culture is an important determinant of campus culture, and their lack of support or even disinterest can be very detrimental to the implementation of a successful tech transfer system. It is critical that the faculty understand the broader vision from their and other institutional leaders, and that they be educated regarding the principles and processes of tech transfer. It is also important to ensure that all faculty, regardless of whether they do research or not, understand the need and reasons underlying the initiative, as all faculty will need to be supportive of modifications in the P\&T and faculty evaluation processes.

When educating faculty regarding the value of tech transfer a study by David Wright is instructive [22]. Wright noted that faculty culture concerning tech transfer is dependent upon informal communication networks, principles of diffusion, history, and social interaction:

Because faculty concerns center on whether commercialization is worthwhile and whether the prevailing university culture permits such activity, their real concerns are not based on policy but on a sense of identity and emotional/professional equilibrium. Therefore, their actions are not strictly in response to policies, but in response to their beliefs about policies and their true impact on professional identity and success. [Tech transfer] and diffusion are inherently social processes that lead to identity formation, not only for the university but for the faculty researchers who comprise the university. For faculty members, altering their identities to incorporate [tech transfer] is a process that relies on communication and ideological support from their peers. Faculty members attempting to develop a "hybrid role" on campuses that have not traditionally supported [tech transfer] may have difficulty reconciling their conflicting identities as commercial researchers and traditional faculty members. [22]
Likewise, it is important that students, particularly graduate or postgraduate students, also begin to be educated around the benefits of tech transfer, entrepreneurship, and commercialization, whether as part of a credit-earning curriculum or as part of their informal education, or preferably both. Finally, in educating faculty and students it is important to ensure that the education is continuous, highlighting best practices and celebrating short-term wins.

Research and discovery are most successful when approached as a "team sport". At the core of successful team science is effective and unfettered sharing of ideas. The process of discovery is further benefited when data and information can be safely shared between groups. It is this sharing that forms the basis of discovery and ultimately leads to important new IP.

Consequently, an important work with the faculty will be around the P\&T and annual evaluation processes. P\&T should not just be about research or scholarly publications. P\&T policies and procedures need to be able to fully recognize and value innovation, entrepreneurship, commercialization, and teamwork. This will require carefully negotiating with faculty governance and departmental leaders.

\subsection{Foster and Support Quality Research, Innovation, and Creativity}

Successful tech transfer begins with innovative and quality discoveries and inventions. The higher the caliber of the research being performed, and the more creative researchers are, the more likely impactful and commerciable ideas and products will be generated. Consequently, leaders must be rigorous and disciplined to ensure their institutions generate the highest quality of research. While most/all faculty in universities will be scholars (i.e. a specialist in a particular branch of study; a distinguished academic), not all faculty are researchers.

Research is not a hobby and not all faculty can or should be researchers. In fact, even at very highly ranked research universities, only $15-30 \%$ of faculty do any significant research. Even less do R\&D that may lead to commercialization. Thus, the establishment of dedicated research units within departments or schools, to create shared spaces and facilities and sufficient critical mass. Because research costs and resources are not unlimited, available support should be reserved for researchers that are truly productive. Leaders should resist calls for having all faculty do research (the primary duty of a faculty member is to teach), or that research support and time is a privilege that is granted to all faculty. It is not. This kind of executive rigor is what has built research university powerhouses worldwide. 
Likewise, leaders should ensure a culture of creativity. What is creativity? Quoting Sir Ken Robinson regarding creativity, "There are two other concepts to keep in mind: imagination and innovation. Imagination is the root of creativity. It is the ability to bring to mind things that aren't present to our senses. Creativity is putting your imagination to work. It is 'applied imagination. Innovation is putting new ideas into practice" [23]. Other observers note that "creativity is the ability to transcend traditional ways of thinking or acting, and to develop new and original ideas, methods or objects" [24], while "innovation is the process of creating value by applying novel solutions to meaningful problems" [25].

Creating a culture of creativity in higher education is not always easy. Higher education is often highly regulated, bureaucratic, and hierarchical, characteristics that are anathematic to a culture of creativity, which requires significant freedom. Creativity is a pattern of thinking. It is about developing and activating the right neural networks, neural networks that allow individuals to make new, and often unexpected, connections.

Creativity is non-linear, but it is logical; it is about new and original thinking by the individual (although the thinking may not be new by historical standards). Creativity involves making critical judgments about whether what one is working on is any good, not just working on anything one chooses. It is not the opposite of discipline, but often requires deep knowledge of what others have achieved and high levels of practical skill. And yes, creativity can be developed and taught. Leaders should strive to understand the fundamentals of creativity and how to develop the skills on their campus, particularly among their community of researchers.

\subsection{Foster, Incentivize, and Create Entrepreneurship Expertise}

The University of California Working Group on Technology Transfer report noted that “.... the University must create a culture of entrepreneurship and innovation... Academic researchers must be engaged in a dialogue with the commercial world" [26]. Successful technology transfer is the fruit of successful innovation and creativity linked with entrepreneurship.

However, few researchers understand entrepreneurship, often defined as "the activity of setting up a business or businesses, taking on financial risks in the hope of profit." In other words, it is the act of building a business around the discoveries and inventions being made. Without entrepreneurship, by somebody somewhere, it is not possible to commercialize any of the innovations faculty (or anybody else for that matter) generate. However, many faculty intuitively reject the idea of commercializing their ideas and discoveries, appropriately preferring instead to 'share it with the world'. In fact, this generosity of spirit and focus on the public good is what make higher education such a powerful force for change.

In order for a tech transfer program to work effectively, all researchers should have a modicum of understanding of what entrepreneurship and commercialization entail. Furthermore, institutional leaders and TTOs should aim to ensure that tech transfer efforts are aligned and supportive of the growing economic engagement responsibility of universities, by including innovation, entrepreneurship, and "economic engagement" programming in their strategic planning processes [19]. The APLU report 'Technology Transfer Evolution: Driving Economic Prosperity' notes that the need for universities pursuing tech transfer to foster an entrepreneurial culture on campus, including developing entrepreneurship awareness and education for faculty, staff, and students; connecting and aligning across entrepreneurial education efforts; mentoring and entrepreneurs in residence; and institutional policy in support of entrepreneurial culture [19].

A usual tactic to enhance entrepreneurship is for institutions to partner with current or former entrepreneurs, including venture capital (VC) companies. However, while these arrangements may bring needed knowledge to the table, it is important that institutions recognize that they will need to develop the skills internally [27]. External investors will be primarily interested in proven technology, something most university research is not. This gap in research development is what accounts for much of the failure of traditional university tech transfer to yield results [28]. Thus, it behooves universities to help their faculty develop the skills to find funding and to develop their own start-ups and companies. As the UC report noted:

The current funding and investment climate creates challenges in translating early-stage inventions generated by university researchers into commercially valuable products and services. Investments beyond the scope of federal and other traditional research funding agencies are needed to mature technologies and create sustainable business to exploit them to create public benefit and economic value. Private funding for pre-seed and seed-stage investments, even in California, is insufficient to support the translation of many new ideas into businesses that generate economic prosperity for California and the nation. Creating funding for translational and early-stage development programs is of increasing importance to the way universities support economic development in their local and regional economies. [26] 


\subsection{Recognize That Local Or National Cultures Vary and Play an Important Role in Tech Transfer}

Finally, it is important to recognize that one size does not fit all, culturally speaking. Grzegorczy studied the influence of culture on social capital in six American and ten Asian technology transfer offices and organizations involved in technology transfer [29]. Her findings suggested that culture can influence creation and utilization of social capital in university-industry links. Culture appeared to influence not only relationships with external stakeholders in technology transfer (industry, governmental bodies), but also internal relationships and management styles in TT offices (influences on organizational culture). For example, comparing Asian TTOs versus American TTOs, management styles were found to be dominating authoritative, directive, and hierarchal versus dominating participative, communication style was formal and indirect versus informal and direct, and networking style involved food versus drinks, respectively.

Moortel and Crispeels compared the Chinese and Western perspective regarding international university-university collaborations on technology transfer [30]. They observed different entry modes and pathways for international university-university technology transfer. The dominant Chinese perspective was to enter these collaborations formally and with substantial resource commitments, while the dominant Western perspective suggested a more informal entry mode without the creation of a new entity. The Chinese pathway to these international university-university collaborations seemed to be based on generating mutual confidence through formal arrangements and on replacing formal safeguards by informal arrangement as the collaboration matured, while the Western perspective suggests formalizing collaborations through a greater commitment of resources, which reduces managerial problems and allows collaborative learning. Local and national perspectives and cultures will play an important role not only ion defining university-based tech transfer, but also in how collaborative efforts will expand globally.

\subsection{Summary}

- A successful university tech transfer program requires a change in the culture of academe - a change to make the campus more 'tech transfer friendly'.

- While recognizing that local or national cultures vary and play an important role in tech transfer, creating a campus culture that values, supports, and promotes tech transfer is essential, requiring university-wide commitment, visible leadership, faculty and student engagement, the highest quality of research, and incentivization of both creativity and entrepreneurship.

- P\&T reviews, and academic expectations, should value not only publications, but also patents, and entrepreneurial and commercialization efforts.

- While there may be individuals that drive R\&D, most successful research and tech transfer efforts today involve a team approach, which needs to not only be recognized, but also incentivized.

- University leaders need to be able to: (a) provide a clear vision for the tech transfer initiative, (b) break down siloes, (c) remove barriers, (d) provide resources, (e) hire the right leaders, (f) set appropriate expectations, and (g) ensure fair and faculty-favorable incentives.

\section{Conclusions and the Impact of Covid-19}

University-driven technology transfer is a powerful tool to enhance regional and economic development. However, it is important to recognize that the actual revenue potential for an individual university is limited. Increasing revenue from technology transfer operations is a notoriously unpredictable and lengthy process, and revenue from licensing is dominated by a small fraction of disclosures. In the U.S. in 2011, the top ten revenue-generating universities accounted for $60 \%$ of the total royalty income of all U.S. universities [26]. Thus, tech transfer must be viewed through an economic development lens rather than a purely transactional revenue generating perspective.

Universities that are successful in establishing an effective tech transfer program have a number of characteristics in common. For example, universities that lead the Milken Institute's University Technology Transfer and Commercialization Index [31] actively promote tech-transfer. This takes engaged and dedicated leadership, engaged, and educated faculty and students, and the development of campus culture and processes that promote, support, and incentivize creativity, innovation, quality research, and entrepreneurship. Tech transfer is not only large research-oriented universities, but it is an arena that medium to small institutions can also compete in, albeit at a more limited level.

Finally, the recent COVID-19 pandemic and its aftermath will readily impact many of the processes that play a role in developing a successful university-based tech transfer program. Viewed broadly, COVID-19 will serve as an accelerant for many trends that were developing or were being established, albeit at a slower rate. The already existing financial strain on institutions of higher education will worsen, exacerbated in part because of decreasing enrollments in many parts of the globe, the increasing financial 
stress on potential students, and because of the significant excess capacity existent in the higher education industry in many countries. This may put negative pressure on universities as they consider investing in the development of a tech transfer program, whose gains will be well into the future. The pandemic has and will negatively impact globalization, placing pressure on many international collaborations that were valuable in creating innovative inventions [30]. Furthermore, social distancing, reduced travel, and other mitigation measures against viral transmission will negatively impact the spontaneous sharing of ideas, potentially stifling innovation and collaboration.

Alternatively, COVID-19 will have an accelerating effect on innovation around testing, and the production, particularly local, of testing supplies, vaccines, personal protective equipment (PPE) and ventilators. There will be an increasing emphasis on research and innovation in infectious, pulmonary, and critical care medicine, vaccine technology, and pandemic and disaster preparedness. Researchers and inventors should always understand that it is best, from a commercialization perspective, to leverage current trends [27].

\section{References}

1. R. Grosse, International technology transfer in services. J. Int. Bus. Stud. 27(4), 782 (1996)

2. Association of University Technology Managers (AUTM), Landmark Law Helped Universities Lead the Way. Association of University Technology Managers (AUTM), [Online]. Available: https://autm.net/about-tech-transfer/advocacy/legislation/bayhdole-act. Accessed 18 June 2020

3. U.S. Patent and Trademark Office, General Information Concerning Patents. U.S. Patent and Trademark Office (USPTO), October 2015. [Online]. Available: https://www.uspto.gov/patents-gettingstarted/general-information-concerning-patents\#heading-2. Accessed 18 June 2020

4. World Intellectual Property Organization (WIPO), Patent Cooperation Treaty. World Intellectual Property Organization (WIPO), 1 Apr 2002. [Online]. Available: https://www.wipo.int/pct/en/ texts/articles/atoc.html. Accessed 18 June 2020

5. U.S. Patent and Technology Office, Patent Technology and Monitoring Team, Number of Patents Granted As Distributed By Year Of Patent Grant, (Table A1-1a) Breakout By Country of Origin. U.S. Patent and Technology Office (USPTO), [Online]. Available: https://www.uspto.gov/web/offices/ac/ido/oeip/taf/us_ gov.htm\#PartA1_1a. Accessed 18 June 2020

6. U.S. Patent and Trademark Office, Patent Technology Monitoring Team Report, Patent Counts By Origin And Type - Calendar Year 2018. U.S. Patent and Trademark Office (USPTO), 2018. [Online]. Available: https://www.uspto.gov/web/offices/ac/ido/oeip/taf/data/ st_co_18.htm. Accessed 18 June 2020

7. D. Nag, The Changing Face of University Technology Transfer. IPWatchdog.com, 9 October 2017. [Online]. Available: https:// www.ipwatchdog.com/2017/10/09/the-changing-face-ofuniversity-technology-transfer/id=88853/. Accessed 18 June 2020

8. Association of University Technology Managers (AUTM), Patents Hit Record High: 2018 Survey. Association of University
Technology Managers (AUTM), [Online]. Available: https:// autm.net/surveys-and-tools/surveys/licensing-survey/2018licensing-activity-survey. Accessed 18 June 2020

9. U.S. Patent and Trademark Office (USPTO), Patent Technology Monitoring Team (PTMT), Patenting Trends by NAICS Industry Category. U.S. Patent and Trademark Office (USPTO), 2020. [Online]. Available: https://www.uspto.gov/web/offices/ac/ido/ oeip/taf/naics/doc/naics_info.htm\#naics_categories. Accessed 19 June 2020

10. E. Podlogar, Royalty Payment Agreement and Industry Trends. ktMINE, 940 W. Adams St., Chicago, IL, info@ktMINE.com, 5 October 2017. [Online]. Available: https://www.ktmine.com/ royalty-payment-agreements-and-transacting-industries/. Accessed 31 May 2020

11. The Association of Public and Land-grant Universities (APLU) Task Force on Managing University intellectual Property, Statement to APLU Members of Recommendations on Managing University Intellectual Property. The Association of Public and Land-grant Universities (APLU), March 2015. [Online]. Available: https://www.aplu.org/projects-and-initiatives/research-scienceand-technology/task-force-intellectual-property/

March2015TaskForceManagingUniversityIntellectualProperty.pdf . Accessed 18 June 2020

12. D.M. West, Improving University Technology Transfer and Commercialization. The Center for Technology Innovation-The Brookings Institution, Washington, DC, 5 December 2012. [Online]. Available: https://www.brookings.edu/research/improvinguniversity-technology-transfer-and-commercialization/. Accessed 18 June 2020

13. J. Yang, Core Concept 7: The Overall Patent Process and Costs (Chapter 7). OC Patent Lawyer, 11 April 2018. [Online]. Available: https://ocpatentlawyer.com/lesson/overall-patent-processcosts/. Accessed 18 June 2020

14. D. Roos, How Tech Incubators Work, 19 May 2015. [Online]. Available: https://money.howstuffworks.com/tech-incubators.htm. Accessed 18 June 2020

15. C. Forrest, Accelerators vs. Incubators: What Startups Need to Know. Tech Republic, 25 June 2018. [Online]. Available: https:// www.techrepublic.com/article/accelerators-vs-incubators-whatstartups-need-to-know/\#: :text=Accelerators $\% 20 \% 22$ accelerate $\% 22 \% 20$ growth $\% 20$ of $\% 20$ an,often $\% 20$ more $\% 20$ focused $\% 20$ on $\%$ 20innovation. Accessed 18 June 2020

16. Technology Transfer, Angel Investor News, 2020. [Online]. Available: https://www.angel-investor-news.com/technology-transfer-licensing-intellectual-property-from-universities-to-industry/. Accessed 19 June 2020

17. D. Schwartz, Crowdfunding: Uneasy fit or a new springboard for promising innovations?, Technology Transfer Tactics, 25 July 2012. [Online]. Available: https://techtransfercentral.com/reprints/ ttt/712-crowdfunding/. Accessed 7 Sept 2020

18. S.A. Merrill, A.-M. Mazza, The National Research Council Managing University Intellectual Property in the Public Interest. Washington, DC: The National Academies Press, 2011. [Online]. Available: https://www.autm.net/AUTMMain/media/Advocacy/ Documents/Managing_University_IP_in_Public_Interest_2011. pdf. Accessed 18 June 2020

19. The Technology Transfer Evolution Working Group of Association of Public and Land-grant Universities (APLU)'s Commission on Innovation, Competitiveness \& Economic Prosperity (CICEP), "Technology Transfer Evolution: Driving Economic Prosperity, The Association of Public and Land-grant Universities (APLU), November 2017. [Online]. Available: https://autm.net/AUTM/ media/About-Tech-Transfer/Documents/Technology_Transfer_ Evolution_Driving_Economic_Prosperity_APLU_NOV2017.pdf. Accessed 18 June 2020 
20. Association of American Universities (AAU) Working Group on Technology Transfer and Intellectual Property, Statement to the AAU Membership on University Technology Transfer and Managing Intellectual Property in the Public Interest. Association of American Universities (AAU), March 2015. [Online]. Available: https://www.aau.edu/sites/default/files/AAU-Files/Key-Issues/Intellectual-Property/Technology-Transfer/AAU-Patent-Tech-Transfer-Working-Group-Statement.pdf. Accessed 18 June 2020

21. Association of University Technology Managers (AUTM), Nine Points to Consider in Licensing University Technology. Association of University Technology Managers (AUTM), 6 March 2007. [Online]. Available: https://www.autm.net/AUTMMain/ media/Advocacy/Documents/Points_to_Consider.pdf. Accessed 18 June 2020

22. D. Wright, Communication and cultural change in university technology transfer. J. Tech. Writ. Commun. 43(1), 79-101 (2013)

23. MindShift, Sir Ken Robinson: Creativity is in Everything, Especially Teaching, KQED, 22 April 2015. [Online]. Available: https://www.kqed.org/mindshift/40217/sir-ken-robinson-creativityis-in-everything-especially-teaching. Accessed 18 June 2020

24. K. Morr, What is creativity? The ultimate guide to understanding today's most important ability, 99designs. [Online]. Available: https://99designs.com/blog/creative-thinking/what-is-creativity/. Accessed 2 June 2020

25. J. Dwyer, What is Innovation: Why Almost Everyone Defines It Wrong, di, [Online]. Available: https://digintent.com/what-isinnovation/. Accessed 18 June 2020

26. University of California Working Group on Technology Transfer, Report of the Working Group on Technology Transfer. University of California, October 2012. [Online]. Available: https://regents. universityofcalifornia.edu/regmeet/nov12/f12attach.pdf. Accessed 18 June 2020

27. D. Rao, How University Tech Transfer Can Be Improved With Skills, Forbes.com, 18 October 2017. [Online]. Available: https:// www.forbes.com/sites/dileeprao/2017/10/18/how-university-techtransfer-can-be-improved-with-skills/\#280814e95819. Accessed 18 June 2020

28. S. Andes, Technology Transfer 2.0: Finding economic value in university $R \& D$, The Brookings Institution: Washington, DC, 7 June 2016 . [Online]. Available: https://www.brookings.edu/blog/ metropolitan-revolution/2016/06/07/technology-transfer-2-0finding-economic-value-in-university-rd/. Accessed 18 June 2020

29. M. Grzegorczyk, The role of culture-moderated social capital in technology transfer - insights from Asia and America. Technol. Forecast. Soc. Chang. 143, 132-141 (2019)

30. T. Crispeels, K. De Moortel, International university-university technology transfer: strategic management framework. Technol. Forecast. Soc. Chang. 135, 145-155 (2018)

31. R. DeVol, J. Lee, M. Ratnatunga, Concept to Commercialization-The Best Universities for Technology Transfer. Milken Institute Center for Jobs and Human Capital., April 2017. [Online]. Available: https://milkeninstitute.org/sites/default/files/ reports-pdf/Concept2Commercialization-MR19-WEB.pdf. Accessed 18 June 2020
Prof. Richard S. Katzman has over 40 years of experience in strategy, business development, business operations and finance in both for-profit and not-for-profit health services organizations. He currently serves as Executive Vice President of Operations at the Lundquist Institute [TLI] located in Los Angeles. In this role, he oversees and directs the business support infrastructure for this independent bio-medical research institute. This includes oversight for virtually all aspects of institute operations including Research Administration, Facilities and Maintenance, Information Services, Industry Sponsored Research, Compliance, Investigational Drug Services, Environmental Health and Safety, Core Equipment Services, and the Vivarium. Prior to TLI, Mr. Katzman was the Chief Strategy Officer at El Camino Hospital, a 400-bed 2-campus community health system located in northern California. In this capacity, Mr. Katzman led strategy and business development along with providing administrative oversight for 7-clinical service lines. From 1997 to 2014, Mr. Katzman held leadership positions at Cedars-Sinai Medical Center in Los Angeles, including Vice President of Business Development, leading strategy and new business development for the medical center, research institute, and its multi-specialty medical group. He also served as Vice President of Academic Affairs, with operational and financial responsibility for Cedars-Sinai's academic enterprise, including grants administration, academic IT, academic department financial operations, technology transfer, graduate medical education, continuing medical education and several other departments that provided the support structure for research, teaching and a faculty of $450+$ clinicians and researchers. Mr. Katzman received his BS in Finance from the American University in 1976 and a Masters in Health Services Administration from the University of Arizona in 1980.

Prof. Ricardo Azziz is an educator-scientist-executive with over 25 years of leadership experience in higher education, research, and academic health, Dr. Azziz currently serves as Chief Executive Officer, the American Society for Reproductive Medicine, the largest international multidisciplinary organization dedicated to the advancement of the science and practice of reproductive medicine with over 8000 members in 100 countries. He previously served as Chief Officer of Academic Health \& Hospital Affairs, State University of New York (SUNY) System Administration, the largest university system in the nation. In this role he provided support, strategic oversight, guidance, and advocacy for the educational, research and clinical programs within the SUNY academic health and health professions portfolio. Dr. Azziz also served as founding President of Georgia Regents University (GRU, now Augusta University), one of four comprehensive public research universities in Georgia, and founding CEO of the Georgia Regents Health System (GRHS, now Augusta University Health System). Dr. Azziz also served as president of the Georgia Health Sciences University (GHSU) and was tasked then with creating the state's only public academic health center, now including GRHS. He was then tapped to lead the successful consolidation of GHSU and Augusta State University to create GRU. Previously, he also served as Assistant Dean for Clinical \& Translational Sciences (CTS) and Deputy Director for the CTS Institute at UCLA, among other positions. Dr. Azziz is also an internationally recognized clinical \& translational researcher, developing an important internationally-recognized program in androgen excess research, and is an accomplished visual artist. He is author of over 500 publications and texts, including 'Strategic Mergers in Higher Education', published by Johns Hopkins University Press. Among other positions, Dr Azziz serves as Research Professor, Dept. of Health Policy, Management and Behavior, School of Public Health, University at Albany-SUNY, and Fellow, Rockefeller Institute for Government. He earned an M.D. from the Pennsylvania State University, and Masters degrees from the University of Alabama at Birmingham. Professor Azziz is a member of the KAU IAB. 
Open Access This chapter is licensed under the terms of the Creative Commons Attribution 4.0 International License (http:// creativecommons.org/licenses/by/4.0/), which permits use, sharing, adaptation, distribution and reproduction in any medium or format, as long as you give appropriate credit to the original author(s) and the source, provide a link to the Creative Commons license and indicate if changes were made.
The images or other third party material in this chapter are included in the chapter's Creative Commons license, unless indicated otherwise in a credit line to the material. If material is not included in the chapter's Creative Commons license and your intended use is not permitted by statutory regulation or exceeds the permitted use, you will need to obtain permission directly from the copyright holder.

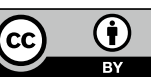

